Vol. 10(16), pp. 2331-2339, 23 August, 2015

DOI: $10.5897 / E R R 2015.2425$

Article Number: 861648154784

ISSN 1990-3839

Educational Research and Reviews

Copyright (c) 2015

Author(s) retain the copyright of this article

http://www.academicjournals.org/ERR

\title{
An analysis of the quality assurance policies in a Ghanian University
}

\author{
Joseph Attiah Seniwoliba* and Richard Nalarb Yakubu \\ University for Development Studies, P. O. Box TL 1350, Tamale, Ghana. \\ Received 30 July, 2015; Accepted 13 August, 2015
}

\begin{abstract}
The study examined the implementation challenges of quality assurance in public universities in Ghana with a focus on University for Development Studies (UDS). The study adopted a qualitative case study design. The data for the study was collected through in-depth interviews, document analysis and participants observation. The study revealed that the Directorate of Academic Quality Assurance (DAQA) undertakes many activities geared towards quality assurance and enhancement of quality in the University. The findings of the study suggest that UDS has taken pragmatic steps to assure quality in its operations. However, the implementation challenges of quality assurance include: staffing and offices; quality culture; physical and financial resources; commitment and support for quality assurance; and absence of a current strategic plan. The author recommends that as a multi-campus University, there should be staff and offices on each of the Campuses for effective coordination of quality assurance activities. The study concludes that the Directorate of the Academic Quality Assurance should be supported to develop a quality assurance culture in the University.
\end{abstract}

Key words: Quality assurance, challenges, establishment, directorate, university.

\section{INTRODUCTION}

Quality has become a very important issue in higher education institutions toward gaining competitive advantage in this changing and dynamic environment. Quality has been an implicit concern of higher education institutions since the establishment of the premier university in Ghana in 1948 and its subsequent elevation to autonomous status. Chacha (2002) therefore argues that universities all over the world are supposed to be characterized by quality and excellence, equity, responsiveness and effective and efficient provision of services, good governance and excellent management of resources.
The rapid changes in the higher education context driven by political, economic and socio-cultural forces in the latter part of the 20th century have generated concern for quality and created challenges to the implicit and self-evident traditional views about assuring quality in universities (Massy, 2003; Amaral, 2007; Martin and Stella, 2007; Becket and Brookes, 2008). The major changes include: massification of education, greater diversity in terms of programme provision and student types, matching programmes to labour market needs, shrinking resources, heightened accountability and indirect steering of higher education. These have brought

*Corresponding author. E-mail: attiahjoseph@yahoo.com. Tel: +233 208725125.

Authors agree that this article remain permanently open access under the terms of the Creative Commons Attribution License 4.0 International License 
a call for more formal (explicit and systematized) quality assurance schemes than was needed in the traditional elite universities (Brennan and Shah, 2000). As a result, various countries all over the world have adopted formal quality assurance systems with the purpose to regulate and improve quality of their higher education systems.

Despite the lack of consensus over the concept of quality, formal quality assurance has now become one of the central components of reform and policy instruments to adapt higher education institutions to the increasing expectations from both internal and external stakeholders all over the world. As Reichert (2008) puts it, quality assurance is so widespread and its vocabulary so pervasive nowadays in higher education policy and discourse that one forgets how relatively recent the enthronement of the term 'quality' actually is. The quality revolution in higher education has underscored the expectation that universities must demonstrate that they are providing quality education and strives to improve it (Anderson, 2006).

In the Sub-Saharan African countries, formal quality assurance is an even more recent phenomenon. The increasing concern for quality in many Sub-Saharan African countries comes at a time from growing recognition of the potentially powerful role of higher education for growth and its rapid expansion since the new millennium (Materu, 2007). In the recent past, many of the Sub-Saharan African countries have implemented higher education expansion policies, which resulted in a significant enrolment growth (McPherson, 2008) within the existing and newly emerging colleges and universities as well as in changes regarding student demographics. The demand for access in many Sub-Saharan countries will increase significantly in the coming years due both to demographic growth and to increased access at primary and secondary educational levels (Shabani, 2007). However, despite the rapid enrolment expansion during the last few years, higher education participation rate in this region has remained among the lowest in the world $(6 \%)$. At present, the major challenges facing many Sub-Saharan African nations include addressing the unmet demand for access through rapid expansion of their higher education improving quality of their education in the context of the prevailing socio-economic, fiscal and political constraints.

A great deal of research work has been conducted in the domain of quality assurance over the past three decades. Despite the progress that has been made through research and debate, there is still no universal consensus on how best to manage quality within higher education (Becket and Brookes, 2008). Much of the research conducted so far focuses on how quality could be defined, on the design and relevance of various national quality assurance schemes, on appraising the applicability of industrial models to higher education, on the tension between improvement and accountability in both external and internal quality assurance approaches, and on the effects of such quality assurance processes in higher education in the context of developed countries (Harvey and Williams, 2010; Pratasavitskaya and Stensaker, 2010).

\section{Statement of the problem}

Since the establishment of the Quality Assurance Unit in 2008, there has not been any empirical research on the implementation challenges of the Unit. Recent studies by Seniwoliba (2014), Okae-Adjei (2012), Tsevi (2014) and Boateng (2014), and Badu-Nyarko (2013) have focused on quality assurance in public universities, polytechnics, private higher education and distance learning respectively. The studies conducted by Seniwoliba (2014) and Okae-Adjei (2012) were generic and focused on student lifecycle framework; Tsevi (2014) examined institutional and programme accreditation; Boateng (2014) assessed barriers to internal quality assurance in private tertiary institutions in Ghana; and Badu-Nyarko (2013) examined quality assurance in undergraduate distance education at the Ghanaian premier university without due consideration for the laid down activities, programmes and the implementation challenges to equip directors of quality assurance department.

In view of the aspects examined by these studies, this study seeks to examine the activities, programmes and the implementation challenges of internal quality assurance of University for Development Studies. The study considered the concepts and challenges of quality assurance practices, the activities and programmes of the Quality Assurance Directorate, the evolution of quality assurance in higher education in Ghana, the University for Development Studies and Quality Assurance as well as the implementation challenges since the establishment of quality assurance in the University. The study therefore seeks to answer questions on the activities and programmes undertaken by UDS and the implementation challenges encountered.

\section{REVIEW OF RELATED LITERATURE}

A number of researches have been conducted on quality assurance in higher education in Ghana. As a result of these most of the writers have raised a number of issues on quality assurance following the establishment of quality assurance units in tertiary institutions in Ghana. In this regard, it is appropriate for this study to provide a synopsis of literature on the subject matter of quality assurance.

According to both Okae-Adjei (2012) and Seniwoliba (2014), the student lifecycle framework looks at how students are admitted, taught and assessed through to their graduation with a focus on quality checks at each stage. In the former study, the author concludes that the 
Koforidua Polytechnic was yet to establish a quality culture in spite of the efforts in place. The latter study also concludes that despite the efforts of ensuring quality assurance in the University for Development Studies, a lot of students who pass through the system cannot graduate and Seniwoliba attributes this bizarre situation to the quality assurance culture.

Tsevi (2014) and Boateng (2014) looked at the quality assurance in private higher institutions but followed different orientations. Tsevi (2014), considered quality assurance from the viewpoint of both the institutional and programme accreditation. This study was generic and looked at quality assurance in private higher education in Ghana. The study concluded that quality assurance has truly brought quality to accredited institutions and implored the $N A B$ to play its watchdog role in monitoring private institutions. Boateng (2014) looked at barriers to internal quality assurance in private tertiary institutions in Ghana. The thrust of the study was on the perception of staff and students selected private tertiary institutions on national quality assurance and the barriers to the implementation of quality assurance requirements by the government quality assurance agencies. The author concluded that private tertiary institutions should imbue the principles of transparency, openness, responsiveness and ingenuity in the development of a quality culture.

Badu-Nyarko (2013) conducted a similar study focused on quality assurance measures that are in place to safeguard undergraduate distance education at the Ghanaian premier university, University of Ghana. BaduNyarko considered quality in the areas of student admissions, orientation, tutorial systems, course development, management, monitoring and examinations. In the assessment of all these areas, Badu-Nyarko concluded there was maintenance of some form of quality assurance geared towards increasing the confidence and integrity of the distance programmes.

According to Bunoti (2011) challenges in higher education are influenced by several factors including, economic factors, political factors, quality of students and faculty, administrative factors and academic factors etc. According to Al-Atiqi and Deshpande (2009), higher education institutions are facing challenges in several fronts; for example, low rate graduations, apprehension among students, rising questions of relevance of college education for public good. Romina (2013) opined that most institutions of higher learning in Nigeria lack staff development programme for training and re-training of staff. Vibrant staff development programme on a continuous basis will help academics and non-academics to clarify and modify their behaviour, attitude, value, skills and competencies. In this way, they grow and develop in their knowledge and thus become more effective and efficient in the performance of tasks. Staff development is paramount because knowledge of today is only sufficient for today. In this era of knowledge explosion and emergent knowledge based economy, staff development should be the priority of any nation. Quality higher education is dependent on the quality and quantity of human and material resources put in place in institutions of higher learning. The lack of infrastructures such as science laboratories, workshops, students' hostels, libraries and electricity will affect the quality of education. For good quality delivery, these facilities must meet the minimum standard specified by the National Council for Tertiary Education (NCTE) and National Accreditation Board (NAB). For quality teaching and learning, the class size must be small for effective students/teacher interaction. Unfortunately, most institutions of higher learning in Nigeria, the lecture halls are overcrowded with majority of the students standing at the corridors during lectures (Romina, 2013: p 7).

\section{Evolution of quality assurance in higher education in Ghana}

Higher education is the facilitator, the bed rock, the power house and the driving force for the strong socioeconomic, political, cultural, healthier and industrial development of a nation as higher education institutions are key mechanisms increasingly recognized as wealth and human capital producing industries (Peretomode, 2007).

World Bank (2004) argued that higher education is fundamental to all developing countries if they are to prosper in a world economy where knowledge has become a vital area of advantage. The quality of knowledge which is generated in institutions of higher learning is critical to national competitiveness. It is only quality education that can sharpen the minds of the individual and help transform the society economically, socially and politically. Countries can achieve sustainable development by improving through training in higher level, the skills of their human capitals.

In pursuance of these benefits the government of Ghana formally introduced quality assurance by establishing the National Accreditation Board (NAB), under the Ministry of Education (MoE). It is a national quality assurance agency responsible for quality assurance in higher education within the territorial jurisdiction of Ghana. It was established by Provisional National Defense Council Law 317, 1993 (PNDCLaw $317,1993)$ which was later amended by an Act of Parliament, which resulted in the enactment of NAB Act 744, 2007. The PNDCLaw 317 mandates NAB as being the sole institution responsible for the accreditation of both public and private tertiary institutions in Ghana in terms of content and standards of programmes. It is also to determine in consultation with professional bodies or institutions in mounting programmes and the maintenance of professional and academic standards. In addition, NAB 
is responsible for determining the equivalents of Degrees, Diplomas and Certificates obtained in Ghana or elsewhere.

The passage of the NAB Act 744, 2007 by the Parliament of Ghana does not only make it to retain the above responsibilities of NAB but also accorded the agency more powers to deal with quality assurance in Ghana. The additional responsibilities which have been assigned to the agency include: publishing the accreditation status of institutions as well as their programmes as deemed appropriate at the commencement of each academic year; and advice the President of Ghana on the grant of a presidential charter to private tertiary institutions. The agency may also perform any other function as assigned to it by the Minister of Education.

Following the PNDCLaw 317 and its subsequent amendment into NAB Act 744, 2007, the NAB made the establishment of Internal Quality Assurance Unit (IQAU) a statutory requirement in tertiary institutions in Ghana. Tertiary institutions that are recognized by $N A B$ are required to establish IQAU within a maximum of five (5) years from the date of first accreditation. According to $\mathrm{NAB}$, the existence of functional IQAU is a key indicator in assessing the performance of an institution towards institutional re-accreditation and the grant of a presidential charter (NAB, 2011).

According to NAB (2011), the functions of IQAU are many and depending on its assigned mandate by the institution, it may perform one of the following functions: review and advise management of the institution's Strong Room; supervise the conduct of examination; facilitate capacity building of academic and support staff within the institution; ensure institutional accreditation process and other quality activities with NAB including annual reporting; facilitate the development, dissemination and application of quality benchmarks for the various academic and administrative activities of the institution; facilitate the collation and integration of feedback from students and other stakeholders on quality related matters in the institution; promote quality culture through the facilitation of workshops and seminars on quality related themes; act as a link agency by coordinating, documenting and disseminating quality matters; develop and maintain a database on quality related information; prepare annual report on quality assurance of the institution based on the quality benchmarks set out for the institution; oversee issues pertaining to the internal and external ranking for the institution and its programmes; managing the institution's affiliation with mentoring institution; and assisting in the development and assessment of curricula.

For the reasons given above, various tertiary institutions particularly public universities/professional institutions and private tertiary institutions have established their quality assurance Units/Directorates/Offices. This is to position the institutions for performance assessment by
NAB on one hand and to make them competitive in the global job market by ensuring compliance with internal quality assurance measures and external (national/ international) standards with the potential to promote comparability of qualifications across institutions of higher learning.

\section{The university for development studies and quality assurance}

The University for Development Studies (UDS) was established by PNDC Law 279, 1992 with the mandate to blend academic work with community development. In fulfillment of its mandate, the university has proved itself as a centre of excellence in the delivery of higher education in the three Northern Regions of Ghana and beyond. This is manifested in its methodology of teaching as well as its demand driven undergraduate and postgraduate programmes, which have attracted prospective applicants within and outside the country. Within just over two decades of its existence, the University has received commendation in the international arena for holding itself as a credible institution for teaching and learning. This achievement is by no means a chance but a conscious effort by the University through the implementation of quality assurance measures. In order to inculcate a quality assurance culture in the University, a Quality Assurance Unit was established in 2008 to handle issues bordering on quality and enhancement.

Currently, graduates from tertiary institutions are in competition for opportunities in the job market across the world. The production of graduates with the right caliber of skills for the job market is an indication of the quality of training from institutions of higher learning. The implementation of quality assurance at both national and institutional level is in the right direction because graduates from tertiary institutions are in an environment defined by local and national needs on one hand and international expectations and standards on the other. The international expectations and standards have increasingly influenced the current wave of enthusiasm given to quality assurance in all tertiary institutions in the world. It is envisaged that educators, policy makers and faculty members appreciate the role of quality assurance and strive for excellence by setting appropriate standards and draw on the uniqueness of local and national needs as well as international expectations and standards in order to make graduates competitive in the global job market (Hayward, 2006).

The establishment of quality assurance into higher education institutions is aimed at addressing issues in higher education. Conscious of this need, developing countries in the West African Sub-region have established agencies to ensure quality assurance and enhance quality in higher education. This is to ensure that higher 
education in developing countries is comparable to those in developed countries (Jonathan, 2000).

\section{RESEARCH METHODOLOGY}

The study was carried out in the University for Development Studies (UDS), Tamale. The University has four satellite Campuses spread across the three regions of the North. The Campuses are Navrongo (Upper East Region), Wa (Upper West Region), Nyankpala and Tamale (Northern Region). The administrative seat of the University is in Tamale, which hosts the Central Administration. The main administrative functions of the University are carried out in the Central Administration implying that all the official correspondence of the university takes place in Tamale. There are also offices of Deans of Faculties/Schools as well as other administrative offices in the Campuses.

\section{Research design}

The study, geared towards understanding the implementation challenges of quality assurance of a multi-campus public university, used a descriptive research design. Bhattacherjee (2012) stresses that descriptive research has the primary aim of doing careful observation and comprehensive documentation of a phenomenon of interest. He noted that such observation is usually guided by the scientific method. The study used a qualitative research approach. Thus, the study relied on the multiple meanings that respondents ascribe to a phenomenon of study based on their experiences (Creswell, 2003). In using this approach, the researcher collected open-ended data in order to probe for further explanation.

\section{Population and sampling}

The university has an academic staff population of 618 (554 males and 64 females). The student population is made up 16,878 males and 6,577 females, making a grand total of 23,455 . Considering the huge numbers and the fact that most of the lecturers have little or no knowledge of the rational for the establishment of the Directorate of the Academic Quality Assurance, the purposive sampling approach was used to select the 12 Deans of Faculties and Schools, 12 Faculty Examination officers, 5 staff of the directorate, 10 lecturers 10 students. The purposive sampling technique is based on the researchers' use of their special knowledge and expertise in the selection of participants for inclusion in the research. This is to ensure that individuals with certain attributes are included in the study. Purposive samples are often used when the goal of the research is to describe a situation rather than generalization (Glassner et al., 1983).

\section{Data collection procedure}

There were two main sources of data for this study: secondary and primary sources. The secondary sources of data were obtained from documented literature including Acts of Parliament that established National Accreditation Board (NAB), National Council for Tertiary Education (NCTE) and guidelines and reports of these agencies. The researchers also consulted books, journals newspaper articles and reports relevant to the study. The primary source of data was obtained from the field using an interview schedule and participants observation. The same interview guide was used for the different categories of respondents in order to ensure triangulation of the various responses. According to Denzin
(1970) triangulation is broadly viewed as the "combination of methodology in the study of the same phenomenon". Denzin drew a distinction between within-method and between-method triangulation. The former which involves the use of varieties of the same method to investigate a research issue was adopted for the study.

\section{Data analysis}

The study used a qualitative data analysis using 2007 Excel spread sheet packages. It simply involves the analysis of non-numeric (qualitative) data from interviews and transcripts. Qualitative analysis of data to a large extent depends on the analytic and integrative skills of the researcher as well as the personal knowledge of the geographic and social context in which the data was collected.

The emphasis in qualitative data analysis is on "sense making" or alternatively understanding the phenomena of interest in the social setting of the study (Bhattacherjee, 2012). Therefore, thematic analysis was employed. To proceed with the analysis, there was data cleaning as the first step. At this stage, the data collected was edited to deal with all errors and uncompleted statements in the course of filling the interview schedule with emphasis on maintaining the original ideas provided by respondents. The researchers then went through the descriptive statements of the respondents in order to identify patterns of responses. This formed the basis for coding and categorization of responses. The analysis was then carried out based on the themes that emerged from the data.

\section{FINDINGS AND DISCUSSION}

Respondents identified the primary functions of the Directorate as ensuring that examination results from the Faculties and Schools of the University are authentic and cleaned devoid of any typographical errors. This is in line with the Directorate's mandate of setting up a vetting committee which vets all examination results on behalf of the academic board. Based on the observations made, the committee may make comments and provide suggestions for any corrections to be effected before they are submitted to the Academic Quality Assurance Directorate. The Directorate in collaboration with Deans and their respective Faculty Examination Officers present the vetted results at the Academic Board Meeting for approval. Once the results are approved, it can be used for processing students' transcripts and attestation letters. In view of this processes, Lewis, et al. (2008) posits that learning organizations are organization skilled at creating, acquiring, and transforming knowledge; modifying its behaviour; facilitating the learning of all its members, and continuously transforms itself.

It was evident from the responses that the Directorate organizes orientation workshops for newly appointed Senior Members (Academic and Non-Academic) in the University where participants are taken through topics such as Preparing to Teach, Teaching Methodology at the Tertiary Level, the new University Lecturer or Administrator, Assessment of Students Learning and Testing, ICT as a tool for Effective Teaching and 
Learning, Demystifying the Quagmire of Conducting an Impactful Research and Scholarly Publishing in Tertiary Institutions as well as Mentoring in the Academia. In this perspective, universities are conceptualized as being both explicitly and implicitly built on notions of relevance to the importance of learning at an individual level. This perspective considers quality of education as a dynamic concept involving continuous improvement and development of members, practices, processes, and outcomes of an educational organization (Cheng and Tam, 1997: p23). The main characteristics of a learning organization such as universities are: learning culture, free exchange and flow of information, commitment to learning, valuing people, climate of openness and trust and learning from experience (Nakpodia, 2009: p80).

Respondents also state that the Directorate periodically conducts routine assessment of courses and or lecturers by students. In this exercise, they mentioned that students are given the opportunity to assess the output of their course lecturers as well as the courses themselves using pre-designed questionnaire. The broad areas identified were; the assessment of exercise provided to students including course presentation, lecturer's demeanor in class, mode of delivery, pedagogy and learning environment. With the exception of the learning environment, the rest of the areas of assessment relate to the lecturer's performance. Respondents revealed that students are also given opportunity to comment either on the lecturer or the course being assessed. The aim of the exercise is to improve quality teaching and learning in the campuses of the University. This idea is not different from the fact that Lim (2001) argues that personal mastery is conjoined to the development of the individual's vision whereas systems thinking involve integrating others into a coherent theory. He therefore concludes that the main purpose of assessing lecturers and courses is to ensure that there are visible signs of implementing successful quality assurance practices in the university which will intend improve students' learning and in the long run provide good job opportunities for grandaunts.

According to the respondents the Directorate of Academic Quality Assurance (DAQA) also conducts periodic monitoring and supervises all trimester examination of lectures as part of the process of assessing both students' and lecturers' response to lectures and collect information from the examination halls using questionnaire respectively. In line with this activity, Barnett (1992), for instance argued that, at whatever level (national, institutional or programme), serious interest in the quality of higher education should entail the improvement of the student experience. Astin (1993) had also the opinion that institutional excellence should be measured in terms of the growth and improvement in students learning. In a similar vein, Tam (2002) noted that 'true quality' depends to a large extent on the institution's commitment to, and interest in the educational and personal development of its students.

According to Dearstyne (1985), records are essential to the administration of High Academic Institutions. Records contain the information that keeps institutional programmes functioning and they give management of higher education a basis for making decisions, administering programmes and providing administrative continuity with past operations. It is in the light of this argument that respondents revealed that the Directorate keeps appropriate and up to date information on the accreditation status of the university programmes; records of affiliated institutions and those in the process of seeking affiliation; copies of examination results; documents of the National Accreditation Board; and records of the National Council for Tertiary Education are also kept to serve as reference materials for managing quality related issues in the University.

Respondents openly asserted that the Directorate considers students as its primary focus. In line with this assertion, it is believed that any university responsive to quality assurance highlights models where students are in the centre of its services. The models should focus on quality of programmes that contribute to the improvement of students learning and development. By this design all the Universities would be working towards enhancing quality of learning and thereby prepare the learner as well as society to face future problems and opportunities. The respondents argued that the quality management framework for higher education should emphasize the conditions that affect quality of student learning. These include a focus on learning outcomes, on curricula, on educational processes, and on quality management. This means that invariably the university will be focusing on the importance of learning and on culture of continuous quality improvement. They said it was in this light that the Directorate vets documents from Faculties and Schools on the curriculum of programme proposals for National Council for Tertiary Education (NCTE) for approval and National Accreditation Board (NAB) for accreditation to meet the tertiary institutions standard in Ghana. In furtherance of this importance, Barnett (1992) argues, that the student's experience is of high quality where there is a process of student development designed to enable students advance to the higher order capabilities, which typify a genuine higher education.

One critical area respondents think the Directorate was greatly closing the gap between lecturers and students was it responsibility of investigating appeals brought to its notice by students and staff on matters bordering on alleged involvement in examination malpractices and assault. Any student who feels aggrieved by sanctions imposed on him/her for any examination malpractice or assault by a lecturer has the mandate to appeal to the Directorate for review and or investigation and subsequent recommendation of the findings to the Vice Chancellor for action. This supports the earlier assertion 
that any good quality assurance model should focus attention on the students being in the centre of its services.

\section{Challenges of the directorate of academic quality assurance}

Tertiary institutions in developing countries including those in the Sub-Saharan Africa region are usually confronted with a number of challenges. One of such challenges identified by respondents was inadequate staffing and the non-availability of offices across the campuses of the University. Despite the fact that the Directorate has many functions to perform, it solely relies on the services of Faculty Officers who most of the time do not carry out the assignments entrusted to them by the Directorate. Badu-Nyarko (2013) in a similar study brought to the fore similar issues on the coordination of undergraduate distance education programmes and attributed the situation to weak linkage between academic departments that run the programmes on one hand and Unit Coordinators and Staff on the other. In cognizance of this assertion, it is only the Director of DAQA in the University who attends quality assurance workshops organized by external quality assurance agencies, while other members of staff in the Directorate are left aloof. Apart from that, there exist no internally planned training programmes to equip the other staff with the necessary skills to make them function adequately. Okae-Adjei (2012) observed that there was inadequate staff at the Quality Assurance Unit of Koforidua Polytechnic which affected the performance of the Unit. He concluded that a few staff in the Unit have very little experience in quality assurance matters. In support of this assertion, Romina (2013) posited that most institutions of higher learning in Nigeria lack staff development programme for training and re-training of staff. Vibrant staff development programme on a continuous basis will help academics and non-academics to clarify and modify their behaviour, attitude, value, skills and competencies. In this way, they grow and develop in their knowledge and thus become more effective and efficient in the performance of tasks.

Respondents discovered the absence of quality culture in the university as a major challenge that has made some members of staff to misconstrue the concept of quality assurance as such, it is viewed as a fault finding unit and mischievous with the intention of implicating staff and so some staff view activities of the Directorate of Academic Quality Assurance with suspicion. Instead of quality assurance being seen as a transformative endeavour of the university which demands collective responsibility, the legitimacy of the Directorate is being challenged in addressing quality assurance concerns in the University. For instance, some academic staff are uncomfortable with the monitoring of lectures at the beginning of each teaching Trimester. Even though, the main rationale for the exercise is to assess lecturers and students' response to lectures performance, it is misconstrued as spying on their service. As a result of this perception, information on quality related matters is often view with some ambivalence from staff. This is evident in the way lecturers perceive the activities of the Directorate of Academic Quality Assurance and one can confidently conclude that considering the present situation, quality assurance is nascent and this may take time for quality culture to be built in the University. OkaeAdjei (2012) and Boateng (2014) also alluded that inconsistent quality culture was a challenge in ensuring quality assurance in tertiary institutions. In the view of the former, he indicated that quality assurance has not been fully embraced by all members of staff and view the Quality Assurance Unit of Koforidua Polytechnic with suspicion. The latter opined that there was dominance culture in private tertiary institutions which hampered instilling a quality culture. He asserted that with a dominant culture coupled with inevitability of change leads to resistance.

The need for physical and financial resources for the effective and efficient actualization of quality assurance activities was another challenge that came out clearly. In spite of the importance of these resources, the researchers observed that office space was limited and crowded with pile up of used papers especially in the general office. The request of the Directorate for laptops, desk top computers and their accessories, projectors, and stationery was delayed beyond the expected time before they were supplied. Besides, that, the amount of financial resources allocated to the Directorate falls short of its annual budget. This budgetary constraint poses a huge challenge to the discharge of the functions of the Directorate. Similarly, Okae-Adjei (2012) in his study noted that the Quality Assurance Unit of the Koforidua Polytechnic was inadequately resourced to enable it carry out its mandate.

Quality assurance thrives in an environment where leadership and management of higher education institutions are committed to ensuring that quality becomes realistic. The study revealed that some Heads of Department (HoDs) and Sectional Heads have not fully committed themselves to assisting the Directorate to carry out quality checks in departments, sections and units within their jurisdiction. Some members of staff perceive the role of the Directorate as interference of their mandatory activities while others term it as "policing". Seniwoliba (2014) pointed out that leadership and management in matters of quality assurance in the University for Development Studies was apathetic and inefficient. Okae-Adjei (2012) in a similar opinion cited inexperienced leadership at the departmental level to deal with issues and problems that border on quality assurance. To buttress this challenge, Romina (2013) 
argued that quality higher education is dependent on the quality and quantity of human and material resources put in place in institutions of higher learning. The lack of infrastructures such as science laboratories, workshops, students' hostels, libraries and electricity will affect the quality of education. For good quality delivery, these facilities must meet the minimum standard specified by the National Council for Tertiary Education (NCTE) and National Accreditation Board (NAB). For quality teaching and learning, the class size must be small for effective students/teacher interaction. Unfortunately, most institutions of higher learning in Nigeria, the lecture halls are overcrowded with majority of the students standing at the corridors during lectures.

The absence of a workable strategic plan was also cited as a factor adversely affecting the institutionalization of quality assurance. However, this purpose of a strategic plan in higher education institutions cannot be glossed over. It sets out the strengths, weaknesses, goals, resource requirements and future prospects of a higher education institution. The strategic plan culminates into the building of stronger and effective higher education institutions for the enhancement of performance and quality. In spite of the importance of a strategic plan, the university has no current strategic plan in place. The first strategic plan for the university spanned from 2003-2008 but has now been outdated and need review to reflect new insights and strategic direction for the university to diversify and make progress. In a similar concern, the Directorate has no strategic plan in place which outlines how quality assurance should be enhanced in the University. In a study conducted by Boateng (2014) it had been revealed that there was weak emphasis on strategic planning in private tertiary institutions.

\section{Conclusion}

The establishment of quality assurance in higher education in Ghana has been phenomenal following the setting up of formal government agencies in the early 1990s. Since the establishment of National Council for Tertiary Education (NCTE) and National Accreditation Board (NAB), quality assurance has firmly taken root in both public and private tertiary institutions in Ghana. As more private tertiary institutions are venturing into the tertiary education sector, it is appropriate that management of public universities such as UDS support the Directorate of the Academic Quality Assurance to succeed in bringing the needed academic quality and enhancement in the University.

\section{RECOMMENDATIONS}

In view of the implementation challenges enumerated above, the following have been recommended for the attention of Management of the University for Development Studies.

1. Management should ensure that the Directorate of Academic Quality Assurance has well equipped offices in all campuses of the University with staff at post. This will go a long way to improve coordination of quality assurance activities across the Campuses.

2. The Directorate of Academic Quality Assurance with the support of Management of the University should create an enabling environment for information dissemination on quality assurance through workshops and seminars for all staff. This will enhance the idea of building a quality culture in the University.

3. The university leadership should at all levels and the Council be involved in and committed to the development and implementation of quality assurance. This shall involve setting the overall direction of the institution towards improvement of quality education, introducing policies and structures for quality assurance with clear responsibility at all levels and monitoring their implementation. In this regard, an institution's leadership and management system is effective if it ensures the active participation of all actors (staff, students, etc.). A professionally capable, credible and visionary leader and/or manager is also crucial in this regard.

4. Management should adequately resource the Directorate of Academic Quality Assurance to carry out it assigned mandate.

5. Management of the University should ensure that a new strategic plan of the university is prepared upon which the Directorate of Academic Quality Assurance can craft its own. The availability of a strategic plan of the Directorate will provide a sense of direction for the growth and enhancement of quality assurance in the university.

\section{Conflict of Interests}

The authors have not declared any conflict of interests.

\section{REFERENCES}

Al-Atiqi IM, Deshpande PB (2009). Transforming Higher Education with Six Sigma. Paper presented at International network of Quality Assessment Agencies in Higher Education, Biannual Conference in Abu Dhabi, 30 March - 2 April 2009. Retrieved fromhttp://www.sixsigmaquality.com/Breakthrough $\% 20$ Solutions $\% 20$ Part\%204\%20of\%205.pdf

Amaral A (2007). Higher education andquality assessment: The many rationales for quality. In: Bollaert, L., Brus, S., Curvale, B., Harvey, L., Helle, E., Jensen, H. T., Komljenovic J. Orphanides, A., \&Sursock, A. (Eds.), Embedding quality culture in higher education: A selection of papers from the 1st European forum for quality assurance. Brussels: EUA.

Anderson G (2006). Assuring quality/resisting quality assurance: Academics responses to 'quality' in some Australian universities, Qual. Higher Educ. 12(2):161-73.

Astin A (1993). WhatMatters in College? Four Critical Years Revisited. NY: John Wiley and Sons, Inc. 
Badu-Nyarko SK (2013). Quality assurance measures in distance learning at University of Ghana. Afr. Educ. Res. J. 1(2):126-133. [Online] Available: http:www.netjournals.org (5th February, 2015)

Barnett R (1992). Improving Higher Education: Total Quality Care. Buckingham: SRHE \& Open University Press.

Becket and Brookes (2008) Quality Management Practice in Higher Education - What Quality Are We Actually Enhancing? Journal of Hospitality, Leisure Sports and Tourism Education; Vol. 7, No. 1. ISSN: 1473-8376 www.heacademy.ac.uk/johlste

Bhattacherjee A (2012). "Social Science Research: Principles, Methods, and Practices". Textbooks Collection. Book 3. [Online] http://scholarcommons.usf.edu/oa_textbooks/3

Boateng JK (2014).Barriers to Internal Quality Assurance in Ghanaian Private Tertiary Institutions. Research on Humanities and Social Sciences, 4(2). [Online] Available: http://www.iiste.org (5th February, 2015)

Bunoti S (2011). The Quality of Higher Education in Developing Countries Needs Professional Support. Paper presented at $22^{\text {nd }}$ International Conference on Higher Education. Retrieved from http://www.intconfhighered.org/FINAL\%20Sarah \%20Bunoti.pdf

Brennan J, Shah T (2000). Managing Quality in Higher Education: an international perspective on institutional assessment and change. Buckingham: Open University Press.

Chacha NC (2002). Public universities, private funding: The challenges in East Africa. A paper presented during the international symposium on African universities in the 21s century at university of Illinois urban champaign 25th-27th April 2002.

Cheng Y, Tam W (1997). Multi-models of Quality in Education. J. Educ. 5(1):22-31.

Creswell JW (2003). Research design: Qualitative, quantitative, and mixed method approaches I by John W. Creswel1. - 2nd ed. p.cm Sage Publications, Inc. Includes bibliographical references and indexes. ISBN 0-7619-2441-8 (c) - ISBN 0-7619-2442-6 (pbk.)

Daily Graphic (13th March, 2014). Private Tertiary Institutions accredited by the National Accreditation Board as at December, 2013.

Dearstyne BW (1985). Managing Government Records: A Manual for Local Government Officials in New York State. [Online] Available from: http://www.eric.ed.gov/ [Accessed: 21 February 2009]

Denzin NK (1970). The Research Act in Sociology. Chicago: Aldine

Government of Ghana, Act 744 (2007).National Accreditation Board Act, 2007. Accra: Ghana Publishing Corporation.

Harvey L, Williams J (2010). Fifteen Years of Quality in Higher Education. Quality Higher Educ. 16(1):2-33

Hayward MF (2006). Quality Assurance and Accreditation of Higher Education in Africa. Paper prepared for presentation at the Conference on Higher Education Reform in Francophone Africa: Understanding the Keys of Success. June 13-15, 2006, Ouagadougou, Burkina Faso. [Online] Available: http://siteresources.worldbank.org (22nd December, 2014)

Lewis N, Wambua KB, Ndiku J, Mwaka M (2008). Universities as learning organizations: Implications and challenges. Educ. Res. Rev. 3(9):289-293

Lim D (2001). Quality assurance in higher education: A study of developing countries. Aldershot, Ashgate Publishing.

Martin M, Stella A (2007). External Quality Assurance in Higher Education: Making Choices. Paris, UNESCO/ IIEP.

Massy W (2003). honoring the Trust: quality and cost containment in higher education. Bolton, Massachusetts: Anker Publishing

Materu P (2007). Higher Education Quality Assurance in Sub-Saharan Africa. Status, Challenges, Opportunities, and Promising Practices. Washington DC: World Bank.
McPherson P (2008). "Higher Education in Africa: Making a Link between Intellectual Capital and Regional Development." Testimony before the House Committee on Foreign Affairs, Sub- committee on Africa and Global Health, 6 May. Washington, D.C.: NASULGC.

Nakpodia E (2009). The concept of the university as learning organization: Its functions, techniques and possible ways of making it effective. J. Public Adm. Policy Res. 1 (5):079-083.

National Accreditation Board (August 2010).Guidelines for Affiliation. [Online] Available: www.nab.gov.gh (15th January, 2015)

National Accreditation Board (2011).Guidelines for the Establishment of a Quality Assurance Unit. 84th Meeting held on 15th and 16th December, 2011.

National Accreditation Board (2015). Homepage. www.nab.gov.gh/nabsite/index.php

National Council for Tertiary Education Act, 1993 (Act 454)

National Council for Tertiary Education (2015). Homepage. www.ncte.edu.gh/nctesite/index.php

Okae-Adjei S (2012). Quality Assurance Practices in Ghanaian Polytechnics: The Case of Koforidua Polytechnic. Interdisciplinary J. Contemporary Res. Bus. 4: 6 [Online] Available: http://journalsarchieves24.webs.com (5th February, 2015)

Peretomode VF (2007) Manpower development and lecturers' productivity in tertiary institutions in Nigeria. J. Educ. Stud., English Edition Poland, 5-11

Pratasavitskaya H, Stensaker B (2010). Quality management in higher education - towards a better understanding of an emerging field. Q. Higher Educ. 16(1):37-50.

Reichert S (2008).Looking back - looking forward: Quality assurance and the Bologna process', in A. Besco, L. et al (eds.), Implementing and using quality assurance: Strategy and practice, the 2nd European Quality Assurance Forum (Brussels: European University Association).

Romina IA (2013) Challenges of Quality in Higher Education in Nigeria in the $21^{\text {st }}$ Century: International Journal of Educational Planning \& Administration. ISSN 2249-3093. 3(2):159-172.

Seniwoliba AJ (2014). Academic Quality Assurance Practices in Ghanaian Public Universities: Experience from University for Development Studies. Global Educ. Res. J. :ISSN-2360-7963: 2(9):152-166, October, $2014 . \quad$ [Online] Available: springjournals. netglobalarticlesinde $=4$.pdf (5th February, 2015)

Shabani J (2007). Shifting Demographics in Sub-Saharan Africa. Int. Higher Educ. 47.

Tam M (2002). University Impact on Student Growth: a quality measure? J. Higher Educ. Policy Manage. 24(2):211-218.

Tertiary Institutions (Establishment and Accreditation) Regulations, 2002 (LI 1700).

Tsevi L (2014). Private Higher Education's Quality Assurance in Ghana. International Higher Education, 75:22-24. [Online] Available: http://ejournals.be.edu (5th February, 2015).

World Bank (2004) Improving Tertiary education in Sub-Sahara Africa: Things that work. Report of a regional training conference, Accra, Ghana. 